\title{
A NOTE ON PITCH CONTROL IN ESOPHAGEAL SPEECH
}

\author{
A. TRAILL (M.LITT. (EDIN)) \\ Department of Linguistics, University of the Witwatersrand, Johannesburg.
}

\section{SUMMARY}

An unusual case of esophageal pitch control first discussed in this Journal is re-examined in the light of additional data. It is claimed that high-pitched stressed vowcls show cvidence of diplophonia, a possibility not described in earlicr studies of this case.

\section{OPSOMMING}

'n Buitengewone geval van esofagale toonhoogte kontrole wat van te vore' in hierdie Tydskrif bespreek is, is wecreens ondersoek in die lig van addisionele gegewens. Daar word beweer dat hoè toonhoogte klem-vokale tekens toon van diplofonie, 'n moontlikheid wat nie vroeër in hierdie geval beskryf is nie.

In two papers, ${ }^{1,2}$ published in this Journal, L. W. Lanham and W. A. Kerr (LK) discuss a case, Mrs B. McL, who had two modes of esophageal phonation, a low-pitched mode and a high-pitched mode. The case is noteworthy not only because of the impression created during speech of wide pitch variation (so much so that it is known to have deceived . . . even the most experienced ear as to the true nature of the voice), ${ }^{2}$ but also because the high-pitched mode of phonation is rare amongst laryngectomees.

LK claim that the two modes of phonation alternate in speech, and that the transitions from one to the other are abrupt. The mechanism for pitch regulation therefore does not involve a continuous variation of tension in the esophageal sphincter but a switch from one vibratory source to another. It is of interest to learn that the esophageal sphincter is the vibratory source for both high and low-pitched phonation. LK's Figures D2 and D3 from their earlier paper (reproduced below as Figures 1 and 2) illustrate the two adjustments of the sphincter for the low- and high-pitched modes of phonation respectively.

The acoustic output of the configuration in Figure 1 is described by $\mathrm{LK}^{1}$ as consisting of . . vibrations of low frequency in the form of noise bursts lacking a harmonic structure ... and that of Figure 2 as consisting of ... pressure pulses with a harmonic structure and true frequency modulation...

The purpose of this note is to present additional data from this case which suggest that LK's account is incomplete. The acoustic evidence presented below indicates firstly that both modes of phonation may take place at the same time and secondly (indeed as evidence for the first claim) that both modes may produce pulses with harmonics. This complex mode of phonation thus constitutes a third type. 


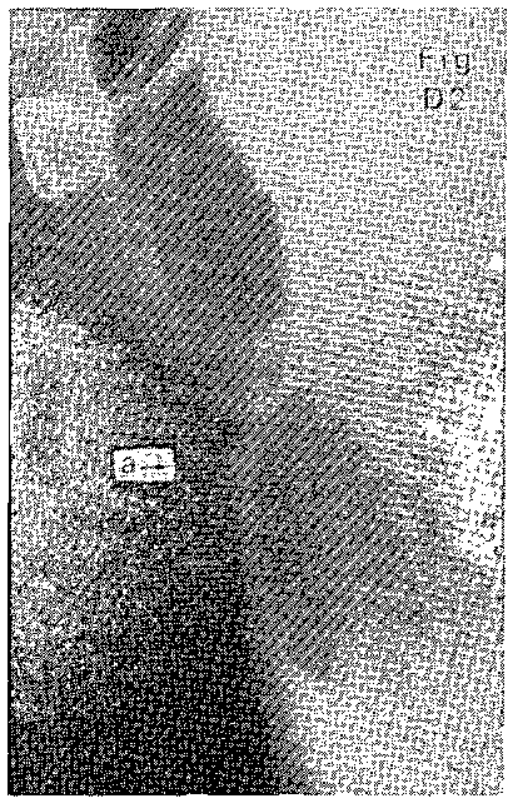

Figure 1. LK's Figure D2 showing the cricopharyngeal articulation during low-pitched esophageal phonation.

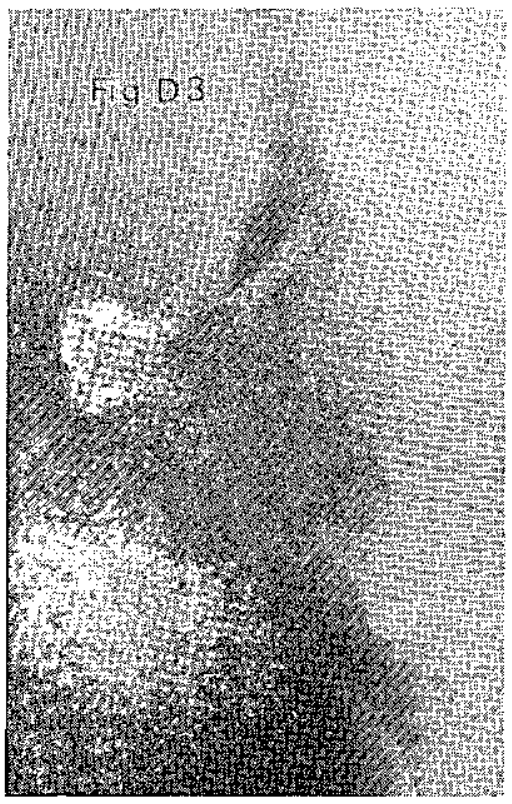

Figure 2. LK's Figure D3 showing the cricopharyngeal articulation during high-pitched esophageal phonation.

This investigation was prompted by a recording of conversational speech produced by Mrs McL. An auditorily prominent feature of the pitch variation was that a particularly high pitch appeared with long stressed vowels, as part of "expressive intonation". The "voice" quality at these points was distinctive, giving an impression of being "squeezed" and mildly harsh. Scale magnified spectrograms were made of 20 secs. of speech in order to establish the acoustic nature of this peculiar auditory effect. In almost every case of these auditorilydetermined pitch prominences, there was evidence of diplophonia. Figure 3 illustrates the relevant sections of the spectrograms. At the points marked with arrows there are unrelated harmonics. Figure 3(a) shows clearly how a harmonic at about $1,28 \mathrm{kHz}$ varies in pitch independently of the one at about $0,43 \mathrm{kHz}$ which remains, largely level. In Figure 3(b) and (c) one can see pitch differences between two pairs of successive harmonics, one pair, rising and falling in pitch while the other pair remains stationary. These unrelated pairs are therefore not harmonics of the same fundamental frequency (Fo). Unrelated harmonics that vary in pitch in these ways are readily detectable. However, it is obviously not necessary that unrelated harmonics should show precisely these kinds of pitch variation; they may in fact have the same pitch pattern and these patterns may be level. In such cases mere inspection is not sufficient to determine relatedness of harmonics and 
it is necessary to calculate whether they could be related to Fo and to one another.

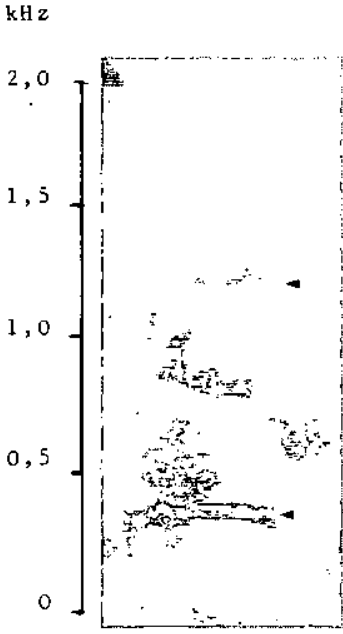

(a)

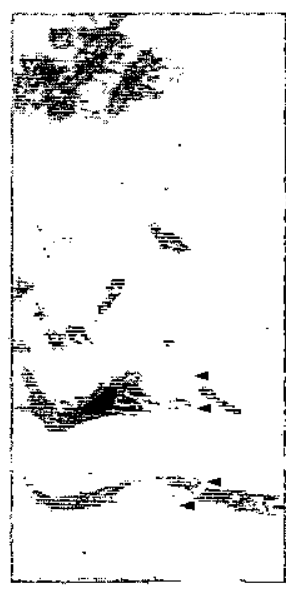

(b)

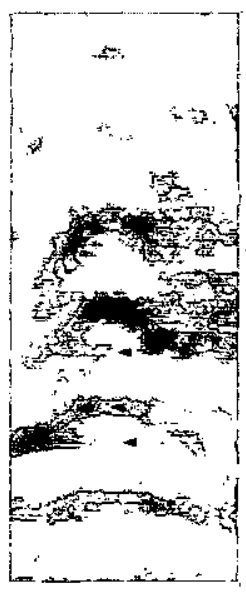

(c)

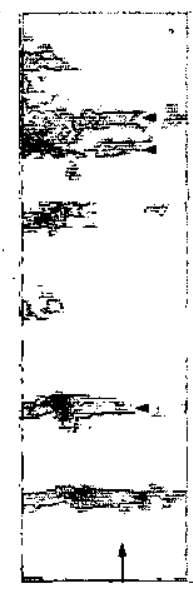

(d)

Figure 3. Narrow band scale-magnified spectrograms of four utterances produced by Mrs McL showing diplophonia. The unrelated harmonics are marked with arrowheads.

Figure $3(d)$ has four clear harmonics with frequencies of $320 \mathrm{~Hz}, 640$ $\mathrm{Hz}, 1610 \mathrm{~Hz}$ and $1720 \mathrm{~Hz}$ at the point opposite the arrow on the baseline. Visual inspection of the different pitch intervals between the higher pair and between the lower pair suggests a possible anomaly. Assuming that the lowest harmonic is the fundamental, then successive higher harmonics are expected at $640 \mathrm{~Hz}, 960 \mathrm{~Hz}, 1280 \mathrm{~Hz}, 1600 \mathrm{~Hz}$, $1920 \mathrm{~Hz}$ etc. The second harmonic occurs at the expected frequency and the next visible one is the lower of the two higher ones at 1610 Hz. Allowing for a margin of error for manual measurement, this will be the fifth harmonic of Fo $=320 \mathrm{~Hz}(320 \mathrm{~Hz} \times 5=1600 \mathrm{~Hz})$. The next harmonic in this series will occur at $1920 \mathrm{~Hz}$, thus showing that the second of the two higher harmonics at $1720 \mathrm{~Hz}$ is not part of the series and must have an independent Fo. Put differently, the vibratory source producing this harmonic is not the same as the one producing the others.

Before leaving this point we should consider the possibility that the relationship between the higher pair of harmonics is actually being obscured by the fact that a number of harmonics are of such weak intensity that they are not visible. For instance assuming Fo $=70 \mathrm{~Hz}$, the fifth harmonic will occur at $350 \mathrm{~Hz}$, the ninth at $630 \mathrm{~Hz}$, the $23 \mathrm{rd}$ at $1610 \mathrm{~Hz}$ and the 25th at $1750 \mathrm{~Hz}$. Once again, the margin of error could account for the discrepancies between these frequencies and those observed in 3(d) and, of course, one would have to assume that 
Fo was not visible. One might thus be tempted to challenge the claim that 3(d) shows evidence of diplophonia. However, this would be incorrect for two reasons. Firstly, a range of 25 harmonics is never found in the acoustic record of this case; nine to ten harmonics seems to be the limit. Secondly, suggestion that there is a weak Fo at $70 \mathrm{~Hz}$ is contrary to the perception of a high-pitched Fo at that point. We may safely accept therefore that 3(d) does show diplophonia.

It is of interest to note that in those cases where the fundamental frequency of the unrelated harmonics is clear, (Figs. $3(b)(c)$ ), it is relatively high for both. Therefore both harmonics may presumably be identified with the crico/pharyngeal adjustment in Figure 2, that is, for Mrs McL's high-pitched phonation. Of course, it cannot be ruled out that a third configuration could have existed corresponding to the cases of diplophonia.

Diplophonia is usually regarded as a bizarre or abnormal type of phonation when the vocal folds are involved. However, in Mrs McL's case this evaluation is hardly appropriate. The diplophonia adds to the perceived range of expressive pitch variation which makes her speech so unusual and satisfactory. It is worth asking whether there is anything distinctive anatomically that could produce so flexible a vibratory source. $\mathrm{LK}^{2}$ claim that Mrs McL's ... pseudoglottal vibration is the product of a relatively intact musculature and considerable effort .... and, as has been noted, they locate it at the site of the cricopharyngeal sphincter in (Fig. 2). They discuss a number of muscular adjustments that distinguish the shape of this sphincter in high-pitched and low-pitched phonation. In their earlier paper they also refer to a pair of antero-posterior folds in the hypopharynx which they claim are ... in apposition during pharyngeal phonation. The latter possibility is not mentioned again in the later paper. The anatomical picture is therefore complex and there is no way to relate it precisely to the acoustic output. However, it may be worth speculating that the "relatively intact musculature" LK refer to could be expected to play a crucial role in producing this unusual type of esophageal pitch control.

\section{REFERENCES}

1. W. A. Kerr and L. W. Lanham. (1973): Anatomical and spectrographic analysis of the voice in disease: a report of five cases. Journal of the South African Speech and Hearing Association, 20, 1, pp, 81-105.

2. L. W. Lanham and W. A. Kerr. (1975): Pitch in esophageal speech. Journal of the South African Speech and Hearing Association, 22, pp. 31-41. 


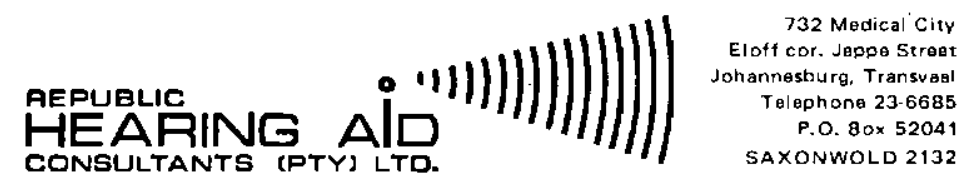

\section{HEARING AIDS.}

WE SPECIALIZE IN

The supply and fitting of Hearing Aids for all hearing losses, especially for

Nerve deafness

Recruitment

Bone conduction cases.

CROSS AIDS:

CROS - BICROS - MULTICROS - etC.

BONE CONDUCTION AIDS for

Body, Earlevel, Glasses (speciality by Viennatone)

\section{BINAURAL FITTINGS}

We import and stock :-

Viennatone, Qualitone, Microson, Phonak hearing aids.

MOULDS:

Soft, hard, skeleton, vented, occluded etc.

REPAIRS:

All aids supplied with a scientific performance report after repair.

SPECIAL PRICES for Dealers and Institutions.

\section{ACCESSORIES:}

Teacher - pupil, parent - child, individual Audiotrainers, very reasonably priced. Group Audio Trainers.

TV - Wireless infrared Transistor Receiver sets made by SENNHEISER.

Audiometers: Screening, Diagnostic, Research, ERA and Electrocochleography C.O.R. and Peep Show.

Impedance bridges.

Manufacturers of Sound proof booth and sound proof rooms.

Hearing Aid testing set by "Fonix" U.S.A.

Phonak noise generator with different frequencies, pure tone and warble tone, for everyday's use.

We repair and calibrate Audiometers.

Sound level meters, calibrators.

Industrial noise consultants.

Die Suid-Afrikaanse Tydskrif vir Kommunikasieafwykings, Vol. 27, 1980 